\title{
Organization of effective interaction between the general contractor and subcontractors using the tools of calendar network planning of construction
}

\author{
Alexander Rudko*, and Marat Kuzhin \\ Moscow State University of Civil Engineering, Moscow, Russia, 129337
}

\begin{abstract}
This article will discuss the advantages of planning using such elements of organizational and technological documentation as a calendarnetwork schedule for a more efficient process of managing the production of work during the implementation of an investment and construction project. Also, the main schemes of interaction between the general contractor and the subcontractor will be considered on the basis of key points of their interaction, such as the construction contract and especially the schedule for the construction and installation work. The article will outline the established and most common way of interaction in the Russian Federation, show its advantages and disadvantages, as well as a more progressive approach aimed at improving the relationship between commercial entities, construction organizations and customers.
\end{abstract}

\section{Introduction}

In the process of implementing modern investment and construction projects, especially projects financed from the state budget, the process of planning and synchronizing both individual types and stages of work and all participants involved in the project is extremely important. Taking into account the fact that at present, not only many different organizations are carrying out work on one project at a time, but also, which is increasingly common, organizations located not even in one city and not even within the borders of one state (international projects), the importance of the designated topics can be traced especially clearly.

In this regard, the planning process using software products that are understandable and accessible to all project participants is vital.

The rapid development of digital technologies and the scaling of the market for software and hardware systems for planning, monitoring and accounting for all processes of an investment and construction project creates favorable conditions for the development of competition, which in turn allows many construction and installation organizations to make a choice in favor of software that best suits their needs. needs, as well as price / quality

\footnotetext{
* Corresponding author: alexander.rudko83@gmail.com
} 
ratio.

Taking into account the fact that customers, both public and private companies, are increasingly focusing on the timing of work without losing quality, a new challenge could be considered the possibility of introducing new information technologies to optimize existing processes and minimize inefficiently used working time by employees of organizations. participants in the investment and construction process.

Taking into account the fact that in our country over the years an environment has been formed in which the acceleration of work, the inability to prioritize and strictly follow the set goals has ceased to be an extraordinary phenomenon, neither planning nor the more efficient use of specialized software in the work was perceived and is not perceived before until now by the vast majority of construction and installation organizations.

The latest global events in terms of quarantine measures, which also affected the Russian Federation, clearly demonstrated a much greater demand for finding more effective methods of project management, minimizing risks and intra-project relationships between all interested construction participants.

The large-scale crisis phenomena, which mainly affected the service sector, unfortunately, did not bypass the construction sector. High volatility of currencies, interruptions in the supply of materials and equipment, staff shortages in the aggregate led to a series of large-scale conservation throughout the country.

Unwillingness to build relationships on the basis of mutually beneficial partnerships, inability to use information and analytical modeling tools in their work and to involve all participants in the production process in this process revealed many unpleasant questions regarding the implementation of construction projects in conditions of lack of time, finances and professional staff.

In this regard, the author set himself the goal of the study: to prove that the use of modern information and analytical software products in the planning process can be not only an effective project management tool, but also a lever of influence on work performers (subcontractors), as well as a tool of mutual discipline and respect for the needs of other organizations participating in the project.

The object of the research is modern information and analytical software products necessary for the development of scheduling and network planning. The subject of this research is the ability of the above software products to act as a legal lever of influence on work producers (subcontractors).

Research author's tasks:

- give details of the stages of interaction between the general contractor and subcontractors;

- track the application of information modeling and planning technologies at the above stages of interaction;

- to determine the effectiveness of information modeling tools as a tool for influencing unscrupulous performers of construction and installation work.

\section{Materials and methods}

In order to gain a deeper understanding of the subject matter, it was decided to resort to detailing the process of interaction between the general contractor and the subcontractor, indicating the stages of such interaction and the possibilities of using information modeling technologies at each of these stages.

Prior to the commencement of work, a construction contract must be concluded between the general contractor and the subcontractor, in which the subject of the contract, the price of the contract and the time frame for the performance of work are the mandatory 
conditions.

Despite the fact that the most significant for any contractor will always be the subject and price of the contract, the timing of the work is essentially the starting point in understanding the first two positions.

As noted above, the timely execution of work is a priority for the Customer, therefore an integral part of the contract is the work schedule (hereinafter GPR), with an indication of specific terms.

In connection with the ongoing process of transformation of methods of control and management of work on the construction of specific facilities, the attitude towards goal setting is also changing when using such a tool as a work schedule.

This tool is increasingly acquiring the character not so much of fixing certain time milestones as, in a sense, a roadmap of the sequence in the implementation of design solutions and related issues of a logistic and administrative nature.

In other words, we get a tool, the consistent implementation of the provisions of which will allow the organization to perform its work efficiently, on time and with the expected positive financial and economic effect of its implementation in the form of project profitability for the contractor.

Realizing this, many organizations change their attitude to this tool for the production of work, and at the stage of its development they take an active part in the process of agreeing on certain stages and sequence of technological chains.

Taking into account the above, it became necessary to highlight the most popular and currently used schemes of interaction between organizations participating in the implementation of a construction project.

Schematically, the process of monitoring and managing the work of subcontractors can be represented as a relationship between two systems, traditional and proactive (partner).

It should be noted that calling the scheme traditional, the more generally accepted format of interaction between construction participants is taken into account, in other words, the most common method of intra-project communication.

This does not mean that such a format of interaction is universal or scientifically grounded, it is rather a generally accepted model of behavior and interaction that was formed spontaneously and due to the national mentality.

The traditional scheme of interaction between the structures of the general contractor and subcontractors looks like this (Fig. 1).

This approach is exclusively formalized and does not take into account the multifactorial risks of the construction project implementation process, in particular, the circumstances of the economic / financial plan (unstable exchange rates, reduction of financing programs, optimization within the Customer's structures, etc.), as well as situations in which force majeure circumstances formally, for various reasons, they cannot be introduced by the Government of the country, but in fact they appear to be exactly the same (for example, quarantine measures COVID-19).

In addition, it is important to note that the above approach in the interaction between the organizations participating in the implementation of the project went through the path of its formation in not the most stable years, which certainly left a certain imprint on many models of relationships in the framework of the implementation of specific projects.

This scheme is most understandable for those Russian organizations that have gone through their path of formation over the past 30 years, it has a rigid hierarchical structure, a certain uncompromising attitude, directiveness, a desire to implement the project by any means and forces, often without taking into account the interests and experience of other participants. 


\section{Traditional way}

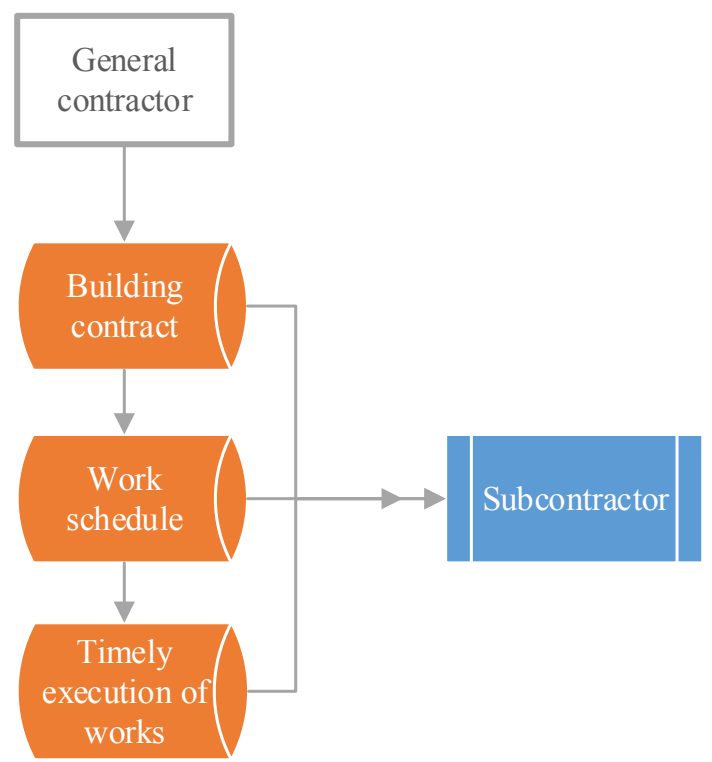

Fig. 1. Traditional way of interaction

Despite the fact that the desire to complete the task of implementing the project itself can be considered a priori extremely positive, distortions most often continue to occur not at the stage of planning the work sequence itself, but at the stage of implementing this sequence.

This is based on the reluctance of the participating organizations to join efforts to implement the project, and sometimes the inability to build partnerships. In other words, with such a directive scheme for monitoring and managing a project, each participant often has no choice but to perform all the forces and means first of his task (scope of work), even if this will entail further delays in the work of other executing organizations.

Obviously, this approach (interaction scheme) is unpromising, spends more resources for solving related, but not basic tasks, leads to a multiplication of mutual claims and discontent, which together harms common goals and creates an unfavorable background for teamwork.

In this regard, GPR is no longer an empty formality, an annex to a construction contract, but a real tool for managing project risks and finding the most optimal ways out of a crisis situation. And, in this case, a more efficient work with HLP can be represented as follows (Fig. 2). 


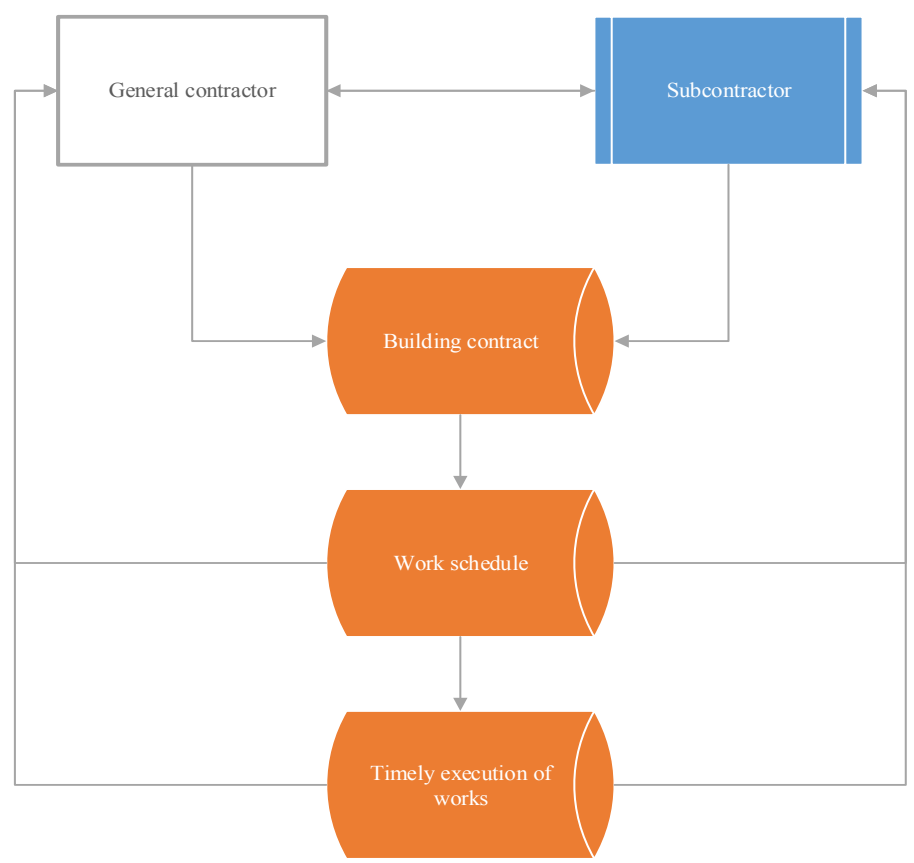

Fig. 2. Proactive (partner) way of interaction

A proactive or partnership scheme of interaction imposes mutual obligations on both parties to the agreement, which makes interaction more effective, since the partner's problems become common problems that need to be addressed, which in turn can create an ecosystem in which partnership is possible exclusively on the basis of full transparency. In addition, a proactive (partner) scheme of interaction initially helps to build relationships between project participants in such a way that a compromise in the search for solutions becomes the cornerstone in the discussion of any issue. In other words, the common goal prevails over the private desires to defend only what is beneficial to one side, but not beneficial to others.

In this case, we can speak not only about the search for compromise solutions within the framework of the project, but also about the fact that the key participants in such a scheme of interaction must commit themselves to its implementation in the production process itself. And this is a necessity, since even with such initially good intentions, in Russian reality one can face the profanation of the very idea of partnership.

The key reason for this most often lies in the fact that agreements and schemes of interaction at a high level between the leadership of the organizations participating in the implementation of the project are not communicated to the subordinate performers at all, and therefore formally the interaction processes seem to be partners, but informally at the level of performers everything remains inside implementation of a construction project, each representative of the participating organization continues, to the detriment of the general goals, to do what is beneficial at the moment specifically to him, without taking into account the technological sequence and stages of their implementation established by the schedule of works.

The logical result of this is that the initial goal of the work schedule, namely, 
minimizing risks and deep decomposition of the technological sequence of performing administrative and coordination, design, construction and installation and other types of work, turns into an endless cycle of adjustments and additions, which becomes the main risk, with which you have to fight.

Therefore, the main task of this form of interaction is to build the relationship between the customer and the contractor in such a way that at each stage it would be possible to quickly receive not only feedback, but also better plan all types of work, taking into account the interests of the parties.

\section{Research results}

The author, as a supporter of the use of modeling technologies and project risk management, repeatedly developed work schedules independently and took part in their development as part of various project teams.

Many years of experience in construction projects for various purposes allows the author to assert: 1) the less deep decomposition of the stages of work (types of work) within the project, the more degrees of freedom the performer has and the more risks of not meeting the deadlines for the work 2) GPR requires joint work of the general contractor and the subcontractor, the deadlines and sequence of work do not correspond to the modern spirit of partnership, and also cause a lot of contradictions and outright confrontation on the part of the contractor, since they do not take into account his professional experience and knowledge, as well as the availability of material -technical base and opportunities to meet the expectations of the GPR developer 3) The GPR must be endorsed with all participants in the construction process, as well as impose severe and inevitable sanctions for its violation 4) The work schedule is a living tool that is constantly subject to adjustments and changes in its basis should be based on the key milestones of the project, but cannot have a rigid and prescriptive nature. We were convinced of this clearly at the events of 2020, when all spheres of activity faced a new reality, namely, working in fact in an emergency situation, but without the opportunity to use the force majeure circumstances section of the contract.

It is not enough to base such a tool as a work schedule only on the professionalism and experience of the operator of special software products; it should first of all be based on the awareness and transparency of partnerships between organizations participating in the project implementation. Understanding of the commonality of the work performed, the mutual desire of partners, if necessary, to support each other with the means and resources they have.

The work schedule allows all construction participants to jointly synchronize their types of work, logistics and create conditions for teamwork instead of individualistic work, since all project participants will benefit from this.

At the same time, GPR can be a very effective means of financial sanctions in the direction of both the general contractor and the performer of the work of the subcontractor, since a deep decomposition of work and joint coordination allows avoiding discrepancies in understanding the implementation of individual stages of the project.

\section{Conclusion}

The author, having set himself the goal of revealing the effectiveness of interaction between the general contractor and the subcontractor on the basis of scheduling and network planning technologies, once again made sure that from how efficiently and professionally the work on project risk management, timing and sequence of construction installation 
work, with the help of such a tool as GPR, essentially depends on the success of the project, its timely completion, effective management of the budget and the quality of construction and installation work.

Nevertheless, in the process of working on the topic and a deeper immersion in the foundations of modern interaction between contractors within the framework of a construction contract, several observations were made that significantly change the viewing angle of the tasks and the topic of the study itself.

Namely, the work schedule is no longer presented as a formal document that does not have the potential for movement and development, which naturally leads us to the following conclusion: the work schedule is a living document that requires constant attention and control.

The foundation of its development should initially be based on the correct priorities and goals, namely, not the desire to use it as a punitive tool with which you can influence the work performer at any time, but as a constructive tool capable of setting the correct priorities in project management and implementation of construction -installation works.

This brings us to an even more interesting discovery: it is not so much how professionally we decompose all stages and individual types of work with its help, it is important how much the issue of the efficiency of financial, economic and production activities in the framework of the implementation of specific projects is a priority for all participants. project implementation.

In other words, we come to the question that the work schedule should become an integral part of the internal culture of project communication, perhaps even the basis for adjusting the traditional schemes of interaction of all project participants.

Modern mechanisms of project management, as well as methods and methods of intraproject communication, offer us a specific choice: effective development or archaic stability.

The importance of the above is that, due to the management models that have been forming in Russia for decades, many changes require, in a sense, the political will or desire of top officials to increase productivity and efficiency in specific areas of activity.

Partnership is always at the heart of any successful interaction, therefore it is necessary not only to use existing tools that improve the microclimate of bilateral relations, but also to constantly look for new ways of more effective partnership.

Scenarios in which the opinion of the performers is always assigned a secondary role are no longer viable. Such models of project development are initially devoid of effective feedback between project participants, create unnecessary tension and distrust.

Network scheduling and work schedule are undoubtedly effective tools in terms of risk control and management, but their effectiveness should be due to the understanding of the fact that this tool is not a formality that should be included in the draft construction contract.

This is a tool that will allow you to identify at the initial stages of planning, those risks that will inevitably arise in the process of implementing any of its parts, and take all the necessary measures in a timely manner to minimize the consequences.

The work schedule is one of the most effective tools in joint work between the general contractor, which allows you to form a new ecological environment in the communication of professional players in the construction and installation services market.

\section{References}

1. A. Lapidus, I. Abramov, Implementing large-scale construction projects through application of the systematic and integrated method, XXIst International Scientific 
Conference on Advanced in Civil Engineering: Construction - The Formation of Living Environment, FORM 2018. "IOP Conference Series: Materials Science and Engineering", 062002 (2018).

2. A.A. Lapidus, Organizational design and management of large-scale and investment projects (Around the world, Moscow, 1997).

3. A. Lapidus, A. Makarov, Automation of roof construction management by means artificial neural network, Advances in Intelligent Systems and Computing 692, 1168 (2017)

4. A.A. Lapidus, V.I. Telichenko, O.M. Terentyev, "Technology of building processes". Part 1 (High School", Textbook for university students, 2002)

5. A.A. Lapidus, V.I. Telichenko, O.M. Terentyev, "Technology of building processes". Part 2 ("High School", Textbook for university students, 2003)

6. S.A. Sinenko, V.M. Ginzburg, V.N. Sapozhnikov, P.B. Kagan, A.V. Ginzburg, Automation of organizational and technological design in construction (Higher education, Saratov, 2019)

7. A.A. Lapidus, V.I. Telichenko, "Information Modeling of Technologies and Business Processes in Construction", "Association of Construction Universities", (2008)

8. A. Lapidus, I. Abramov, A system-integrated approach to the study of the problem of ensuring the sustainability of complex production and dynamic systems in construction, In the collection: Construction system engineering. Cyberphysical building systems A collection of materials from a seminar held as part of the VI International Scientific Conference, 159-162 (2018)

9. I. Abramov, A. Lapidus, Systemic integrated method for assessing factors affecting construction timelines, Collected at: International Scientific Conference Environmental Science for Construction Industry - ESCI 2018 Ser. "MATEC Web of Conferences", 05033 (2018)

10. P.P. Oleinik, The choice of the rational relationship of the method and form of organization of construction, Industrial and civil construction 6, 46-50 (2019)

11. L.A. Pakhomova, P.P. Oleinik, Selection and assessment of parameters for certification of work places sout (special assessment of working conditions), Technology and organization of construction production 1, 49-52 (2019)

12. P. Oleinik, A. Yurgaytis, G. Voronina, A. Makarenko, Methods for the formation and optimization of calendar plans for construction companies, Collected: MATEC Web of Conferences, 05037 (2018)

13. B.V. Zhadanovsky, E.S. Erzhokova, E.A. Gorshkova, Stream method as a way of organizing the construction of System Technologies 3(28), 136-140 (2018)

14. A.A. Zelentsov, A.Ya. Tokarsky, Modeling the consequences of the risks of manifestation of negative factors during the construction of capital construction projects, In the collection: Days of student science. Collection of reports of a scientific and technical conference based on the results of research work by students of the Institute of Construction and Architecture, 1361-1363 (2019)

15. A.A. Lapidus, K.S. Tolstova, D.V. Topchiy, Formation of groups of parameters affecting the criterion of admissibility of combining processes in the production of finishing works, Science and business: development paths 6(84), 18-22 (2018)

16. M.I. Solomatina, Study of the influence of destabilizing factors on the reliability of production processes, In the collection: Days of student science. Collection of reports 
of a scientific and technical conference based on the results of research work by students of the Institute of Construction and Architecture, 1299-1301 (2019)

17. J. Liu, \& M. Lu, Synchronized optimization of various management-function schedules in a multiproject environment: Case study of planning steel girder fabrication projects in bridge construction, Journal of Construction Engineering and Management 146(5) (2020) doi:10.1061/(ASCE)CO.1943-7862.0001813.

18. M. Arashpour, V. Kamat, Y. Bai, R. Wakefield, \& B. Abbasi, Optimization modeling of multi-skilled resources in prefabrication: Theorizing cost analysis of process integration in off-site construction, Automation in Construction 95, 1-9 (2018) doi:10.1016/j.autcon.2018.07.027. 